\title{
Mechanical Performance of Basalt Fibre Reinforced Concretes
}

\section{Zeynep ALGIN ${ }^{1 *}$, Kasim MERMERDAŞ ${ }^{1}$, Lawand Waleed KHALID ${ }^{1}$}

\begin{abstract}
The fresh and hardened characteristics of concrete reinforced with basalt fiber (BF) have been investigated in the presented study. The chopped micro BF with the length of $12 \mathrm{~mm}$ are included in concrete mixes at $0.2 \%, 0.4 \%, 0.6 \%$ and $0.8 \%$ of total volume along with the variation of water to cement ratios (w/c) of 0.47 and 0.59 . Mechanical features of concrete incorporating BF are specified using the parameters obtained from static modulus of elasticity, compressive, flexural and splitting tensile strength tests. The multi objective optimization analyses using response surface method (RSM) is performed by the parameterization of the minimized cost and the maximized performance based on the dependent parameters presented. Test results reveal that the mechanical properties are improved while the workability of concrete is remarkably deteriorated by BF incorporation. The optimization analysis has inferred that the $\mathrm{BF}$ content of $0.356 \%$ provides the optimum result with the w/c ratio of 0.47 .
\end{abstract}

Keywords: Basalt fiber, fiber-reinforced concrete, optimization, strength, workability, response surface method.

${ }^{1}$ Zeynep ALGIN (Orcid ID: 0000-0001-7004-8403), Kasım MERMERDAŞ (Orcid ID: 0000-0002-1274-6016), Lawand Waleed KHALID (Orcid ID: 0000-0003-3426-7646), Harran University, Engineering Faculty, Civil Engineering Department, Sanliurfa, Turkey

* Sorumlu Yazar/Corresponding Author: Zeynep ALGIN, e-mail: zyilmaz@ harran.edu.tr

* This work was produced from the Master's thesis of Lawand Waleed KHALID. 


\section{INTRODUCTION}

Cement based construction materials, especially concrete, are largely utilized in construction industry. Its certain superior properties compared to other structural building materials play an important role for preference. However, it doesn't have proper ductility and high tensile strength, which leads to brittle behavior and low toughness. It exhibits weak tensile behavior because of its low strain energy absorption capacity and the presence of micro cracks and voids. Many fibers like steel, carbon, glass and polymer have been benefited in concrete resulting in significant improvements on the engineering properties such as tensile strength, impact, abrasion and fatigue resistances, ability to deform, energy absorption capacity and load carrying capacity after cracking (Wang et al., 2000; Yazic1 et al., 2007; Mohammadi et al., 2008; Elshafie and Whittleston, 2015).

Basalt fiber (BF) is obtained through the melting process of volcanic rocks at about $1450-1500{ }^{\circ} \mathrm{C}$ which is an environmentally friendly and non-hazardous method (Sim et al., 2005; Fiore et al., 2011; Borhan, 2012; Fiore et al., 2015). Despite the similarity in manufacturing processes of basalt and glass fibers, there is less energy and no additive requirement for BF. As such, BFs possess advantages when compared to the glass and carbon fibers (Deák and Czigány, 2009; Lopresto et al., 2011; Borhan, 2012; Fiore et al., 2015). BF can also be benefited as a newly introduced reinforcement material when considering the relatively common ones such as glass, aramid and carbon fibers in the concrete. This innovative material has advantages such as high thermal and chemical resistance, extremely good modulus and high strength (Jiang et al., 2010; Wei et al., 2010; Wei et al., 2011; Fiore et al., 2011; Borhan, 2012; Wang et al., 2013; Raj et al., 2014).

It has previously been reported that the workability of concrete having BF decreases by the increase in fiber content and length owing to its amount and high surface area which requires extra paste for being coated (Ma et al., 2010; Singaravadivelan et al., 2012; Borhan, 2013). It accordingly decreases the w/c ratio then increases the resistance of fresh concrete against flow which results in the loss of slump. Therefore, the amount of superplasticizer is increased in order to obtain the target slump value (Chen and Liu, 2005; Jiang et al., 2014; Kabay, 2014; Elshafie and Whittleston, 2015).

Kizilkanat et al. (2015) fulfilled a comparative study to observe the strength features of high strength concrete incorporated with four volume fractions of glass and basalt fibers. It was reported that the mechanical properties measured from the concrete produced $0.5 \% \mathrm{BF}$ are increased by $5.1 \%, 13 \%$ and $24 \%$, respectively. It was also emphasized that the inclusion of BF provided better workability and higher mechanical properties compared to glass fiber. Arivalagan (2012) reports that the strength of concrete is enhanced compared to the concrete without BF. The increments in the compressive strength resulting from the concrete with BF are also observed for the fiber content up to $0.3 \%$ by Borhan (2013). Palchik (2011) states that the strength value of concrete including $12 \mathrm{~mm}$ length BF induce the propensity to an increase by 58\%. Ma et al. (2010) however reports that the influence of various content and length of pre-soaked BFs on the compressive strength is insignificant. Kabay (2014) states that the utilization of BF results in decrease of the compressive strength of concrete. Several researches working on the Young's modulus of concrete reinforced with BF found that BF inclusion affected and increased the elastic modulus significantly (Borhan, 2013; Wu et al., 2013; Ayub et al., 2014; Poznya et al., 2014).

In the study of Ayub et al. (2014a) investigating the effect of BF on the strength characteristics of concrete, it was monitored that the average enhancement in the flexural and splitting tensile strength values is $24 \%$ and $27 \%$ for $3 \%$ BF utilization, respectively. Ma et al. (2010) emphasizes that the higher the the cut length of pre soaked BF, the better the tensile strength of the concrete is. Chen (2013) reported the change in tensile strength of concrete incorporated with BF by $19 \%$ after 28 days curing. 
Budkonstruktsiya (2013) investigated the tensile strength of concrete produced with the several length and amount of BF. It is stated that higher tensile strength values are obtained in concrete mixes using 12 mm length and 1-2\% BF. Ketan and Kulkarni (2012) reported that 1 percent BF incorporation reduces tensile strength of concrete.

Jun and Ye (2010) investigated mechanical performance of concrete as a result of various BF levels. It is highlighted that the flexural strength of concrete is enhanced as a result of the increase in the $\mathrm{BF}$ ratio and the highest value is achieved for 3\% BF utilization. Kabay (2014) reports that the inclusion of BF even at low contents improves the flexural strength. Ketan and Kulkarni (2012) expresses that in the case for $1 \%$ BF utilization adversely affects the strength of concrete. Jiang et al. (2014) highlighted that the use of BF remarkably enhances the tensile and flexural strength without resulting a pronounced development in the compressive strength. Alnahhal and Aljidda (2018) investigated the influence of using basalt macro-fibers combined with recycled concrete aggregates from demolition and construction waste on the ultimate capacity and flexural performance of reinforced concrete. It was stated that the addition of different volume contents of BF to the concrete was not effective on the compressive strength of the concrete but caused a significant increase in the bending strength of the concrete. Alnahhal and Aljidda (2018) underline that the significant enhancement in the flexural capacity and ductility of the basalt reinforced concrete beams as compared to control concrete beams were observed.

Because of the low production cost of $\mathrm{BF}$ and the prevalence of the raw material, the utilization of $\mathrm{BF}$ in the application and production industries of concrete has become increasingly widespread. Accordingly, these practical applications of BFs have brought about the need to investigate the impact of BF on the mechanical and workability features of concrete. This paper tackles this issue and presents a comprehensive investigation on the influence of BF incorporation based on the workability and mechanical characteristics of concrete. Moreover, an optimization and analytical study was also conducted for further interpretation of the experimental data.

\section{MATERIALS AND METHODS}

\section{Materials}

In the experimental study, the ingredients used for concrete casting are CEM I 42.5R cement, river sand and coarse basalt aggregates obtained from local quarry, the chopped BF of $12 \mathrm{~mm}$ length is shown in Figure 1. The physical properties as well as chemical composition of the cement utilized in this study are given in Table 1. BF has a specific gravity of 2.78 and a diameter of 14 microns. River sand passing through $4 \mathrm{~mm}$ sieve size was utilized as fine aggregate. The specific gravity and water absorption values are measured as 2.63 and $0.55 \%$ for fine aggregate. The basalt aggregate in the form of two fractions with the range of 4-16 $\mathrm{mm}$ and $8-31.5 \mathrm{~mm}$ was also benefited as coarse aggregate. The physical characteristics of aggregates and the results from the sieve analyses are given in Table 2.

Table 1. Properties of cement used in this study

\begin{tabular}{lc}
\hline Chemical and Physical analysis & \\
\hline $\mathrm{CaO}(\%)$ & 64.15 \\
$\mathrm{SiO}_{2}(\%)$ & 19.18 \\
$\mathrm{Al}_{2} \mathrm{O}_{3}(\%)$ & 5.15 \\
$\mathrm{Fe}_{2} \mathrm{O}_{3}(\%)$ & 3.13 \\
$\mathrm{MgO}(\%)$ & 1.48 \\
$\mathrm{SO}_{3}(\%)$ & 2.50 \\
$\mathrm{~K}_{2} \mathrm{O}(\%)$ & 0.56 \\
$\mathrm{Na}_{2} \mathrm{O}(\%)$ & 0.21 \\
$\mathrm{Loss}$ on ignition $(\%)$ & 3.44 \\
Specific gravity & 3.12 \\
Specific surface area $\left(\mathrm{m}^{2} \mathrm{~kg}^{-1}\right)$ & 293 \\
\hline
\end{tabular}




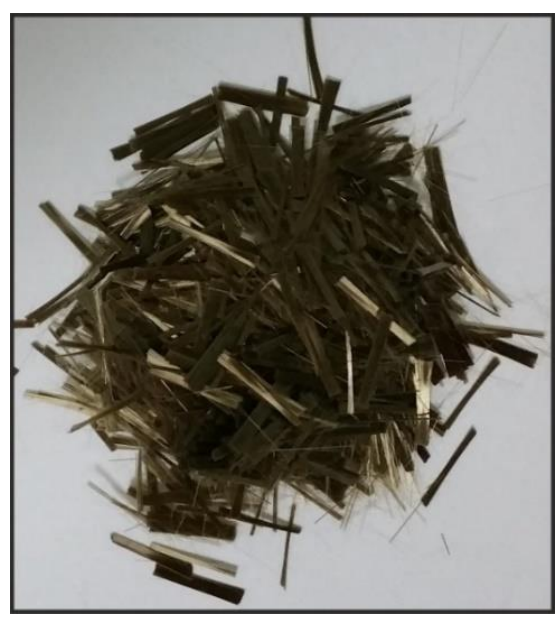

Figure 1. Chopped basalt fiber

Table 2. Sieve analysis and the aggregate properties

\begin{tabular}{|c|c|c|c|c|}
\hline & \multirow{3}{*}{ Sieve opening $(\mathbf{m m})$} & \multicolumn{3}{|c|}{ Passing (\%) } \\
\hline \multirow{10}{*}{ 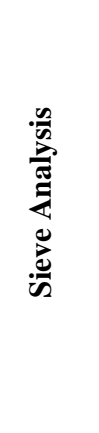 } & & \multicolumn{2}{|c|}{ Coarse aggregate } & \multirow{2}{*}{ Fine Aggregate } \\
\hline & & $8-31.5 \mathrm{~mm}$ & $4-16 \mathrm{~mm}$ & \\
\hline & 31.5 & 100.0 & 100.0 & 100.0 \\
\hline & 16 & 70.4 & 100.0 & 100.0 \\
\hline & 8 & 0.2 & 65.8 & 100.0 \\
\hline & 4 & 0.0 & 1.3 & 99.6 \\
\hline & 2 & 0.0 & 0.1 & 94.8 \\
\hline & 1 & 0.0 & 0.0 & 64.3 \\
\hline & 0.5 & 0.0 & 0.0 & 33.4 \\
\hline & 0.25 & 0.0 & 0.0 & 9.9 \\
\hline \multirow{3}{*}{ 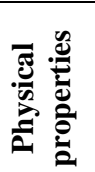 } & Fineness modulus & 6.29 & 5.33 & 1.98 \\
\hline & Specific gravity & 2.87 & 2.85 & 2.63 \\
\hline & Absorption (\%) & 1.17 & 1.28 & 0.55 \\
\hline
\end{tabular}

\section{Details of Mixtures and Casting}

Concrete mixtures were prepared by two different water to cement ratios of 0.47 and 0.59 . The river sand considered as the fine aggregate are used as $45 \%$ of total aggregate weight. Table 3 indicates the detailed mixture proportions of two concrete designs prepared in the current study. In these concrete mixtures, $12 \mathrm{~mm}$ length $\mathrm{BF}$ was used as the volume fractions of $0 \%, 0.2 \%, 0.4 \%, 0.6 \%$, and $0.8 \%$. Accordingly, 10 different concrete mixtures in total were produced in this study. For mixing the concrete mixtures, firstly the cement, aggregates and $\mathrm{BF}$ were added to the concrete mixer and mixed until a uniform distribution of the fibers was visually inspected. The time required for dry blend was prolonged based on the inclusion rate of BF used. Following the dry mixing process, the water was gradually added to the mix within 3-4 minutes. The slump test was conducted to identify the consistency of the fresh mixtures. After slump test, the fresh concrete is poured in the molds. Each mold was placed on the vibrating table and filled by three layers until the concrete was adequately consolidated. The specimens were demolded 1 day following concrete casting and then moist curing is adopted till the testing time.

Table 3. The mix proportions of concrete $\left(\mathrm{kg} \mathrm{m}^{-3}\right)$

\begin{tabular}{lccccc}
\hline Mix No. & Cement & Water & River sand & 8-31.5 mm Coarse Agg. & 4-16 mm Coarse Agg. \\
\hline Mix 1 & 521.3 & 245 & 701.3 & 358.5 & 498.7 \\
Mix 2 & 393.2 & 232 & 768.3 & 392.7 & 546.3 \\
\hline
\end{tabular}


Mechanical Performance of Basalt Fibre Reinforced Concretes

\section{Testing}

The experimental test program was planned to assess how the amount of BF influence the mechanical behavior of concrete. In the present study, consistency of concrete was evaluated via slump test while the improvement in mechanical properties were monitored by static modulus of elasticity, compressive, flexural, splitting tensile strength tests (Figure 2).

To determine the compressive strength of concrete, the samples of $150 \times 150 \times 150 \mathrm{~mm}$ were tested per ASTM C39 (2018). The splitting tensile strength was tested on the cylindrical specimens of 100x200 mm according to ASTM C496 (2017). The static modulus of elasticity test was performed using cube samples of 150x150x $150 \mathrm{~mm}$ by complying with ASTM C469 (2014). The flexural strength test was conducted using beam samples with the dimensions of 100x100x400 mm in accordance with ASTM C78 (2016). All tests were done on three samples at 28 days from each mixture. The test result was determined for each mix by averaging three single values obtained from the tested specimens for each mixture.

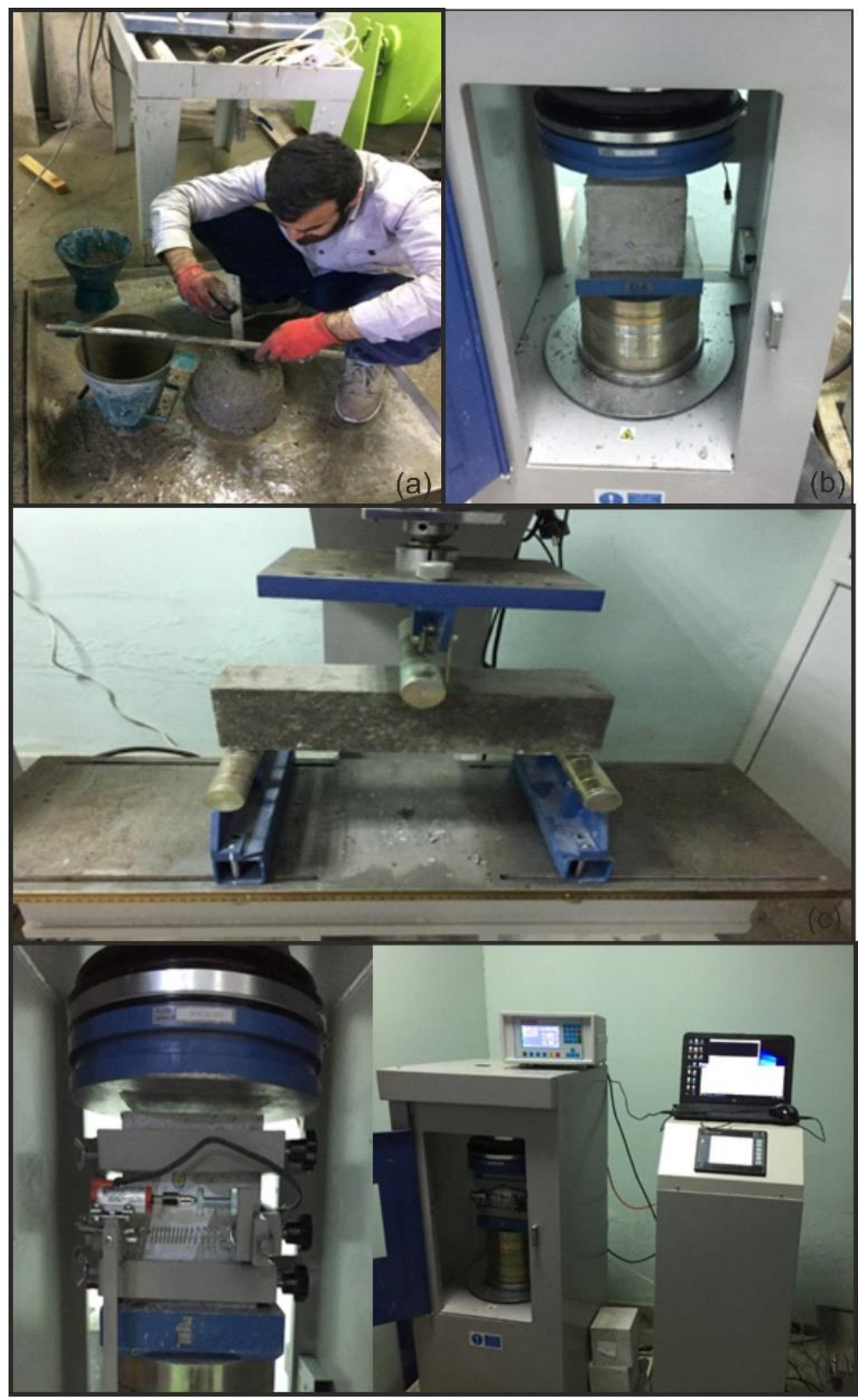

Figure 2. Tests conducted in this study (a) slump, (b) compressive strength, (c) flexural strength and (d) static modulus of elasticity 


\section{RESULTS AND DISCUSSION}

The slump test results obtained from the concrete mixes prepared with the two different w/c ratios and various BF content are given in Figure 3. Figure 3 shows that the slump values gradually decrease with an increasing amount of $\mathrm{BF}$ for the both w/c ratios. The control mixes have the slump values of 18 $\mathrm{cm}$. The use of $0.8 \% \mathrm{BF}$ in concrete induces a decrease approximately $61 \%$ and $56 \%$ for 0.59 and 0.47 $\mathrm{w} / \mathrm{c}$ ratios, respectively. These reductions in the slump test results are attributed to the network structures which are formed due to the BFs scattered in the concrete. This structure causes to restrain the mixture from segregation and flow. Owing to the high fiber content and large fiber surface area, the BFs are able to absorb more cement paste wrapping around, which increases the viscosity of mixture and subsequently leads to the loss of slump (Chen and Liu, 2005). The higher the BF content is, the more viscous the concrete becomes. Therefore, high BF utilization can be proposed for the conventional concretes of plastic or stiff consistency. Increasing the amount of superplasticizer to improve the workability of high BF included concrete may lead the problems of bleeding and segregation.

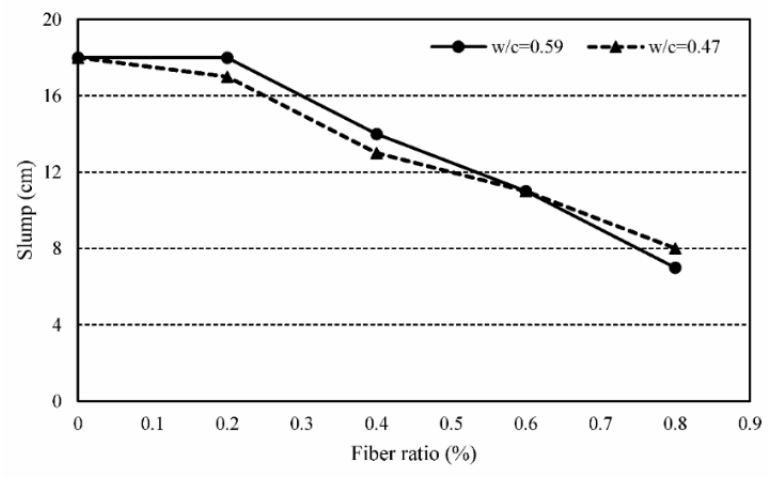

Figure 3. Variation of slump values for the concrete with BF

Figure 4 presents the effectiveness of using varying BF content on the compressive strength values. The lowest compressive strength values were obtained from the control samples (see Figure 4). The addition of BFs to the concrete slightly increases the compressive strength as a result of the crack arresting mechanism of some parts of the included fibers. Comparing to the control mixes, the increments in compressive strength resulted from $\% 0.8 \mathrm{BF}$ inclusion are about $16 \%$ and $10 \%$ for 0.59 and $0.47 \mathrm{w} / \mathrm{c}$ ratios, respectively. Another aspect for enhancement effect of BF can be found in the study of Solikin (2012). He states that the high content of $\mathrm{SiO}_{2}$ in $\mathrm{BF}$ reacts with $\mathrm{Ca}(\mathrm{OH})_{2}$ resulting in the hydration of Portland cement, accordingly the amount of secondary CSH that improves the strength of concrete gradually develops.

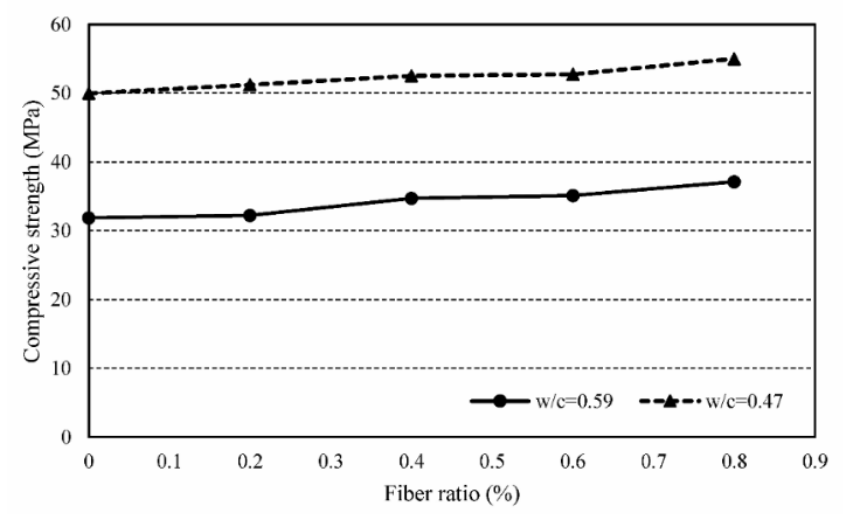

Figure 4. Variation of compressive strength results 
Figure 5 indicates that the utilization of BF induces an increase in the flexural strength of concrete due to the rise in the $\mathrm{BF}$ content for 0.59 and $0.47 \mathrm{w} / \mathrm{c}$ ratios. The 28 -day flexural strength values of all mixtures exceed the strength value of the control specimens. The flexural strength values of the concrete specimens ascend gradually as the ratio of BF increases from 0 to $0.8 \%$ for the both w/c ratios. The increments in flexural strength are about $21 \%$ and $17 \%$ for 0.59 and $0.47 \mathrm{w} / \mathrm{c}$ ratios, respectively. Considering the flexural strength performance of the concretes, the utilization of $0.8 \% \mathrm{BF}$ appears to be promising.

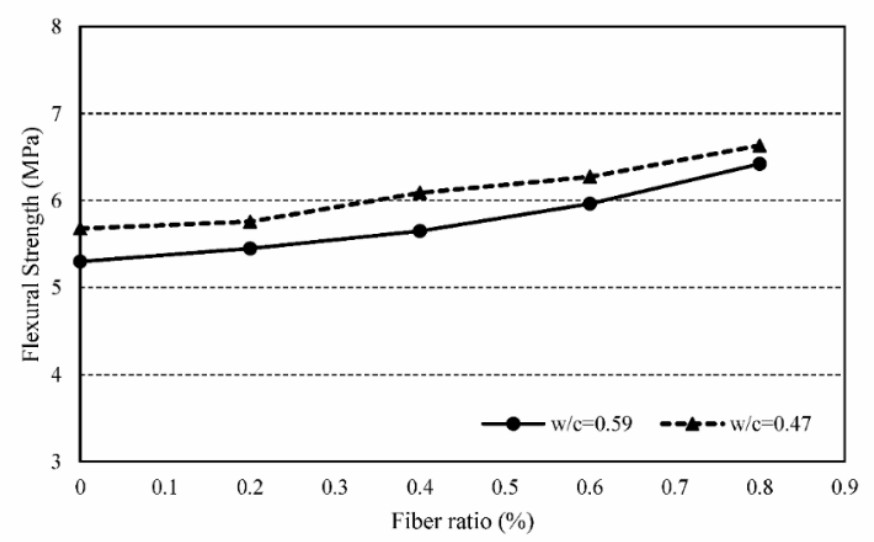

Figure 5. Variation of flexural strength results

The results of splitting tensile strength test for all concrete sample produced with the two different w/c ratios are given in Figure 6. The utilization of BF induces the propensity to an increase in the splitting tensile strength (see Figure 6). It is observed that splitting tensile test results is increased by the increment in the amount of fiber for the both w/c ratios. The highest value of splitting tensile test is obtained from the concrete sample produced with $0.8 \% \mathrm{BF}$ incorporation. Comparing with the control sample, the splitting tensile test results for the samples with $0.8 \%$ BF incorporation are increased by about $34 \%$ and $26 \%$ for 0.59 and $0.47 \mathrm{w} / \mathrm{c}$ ratios, respectively.

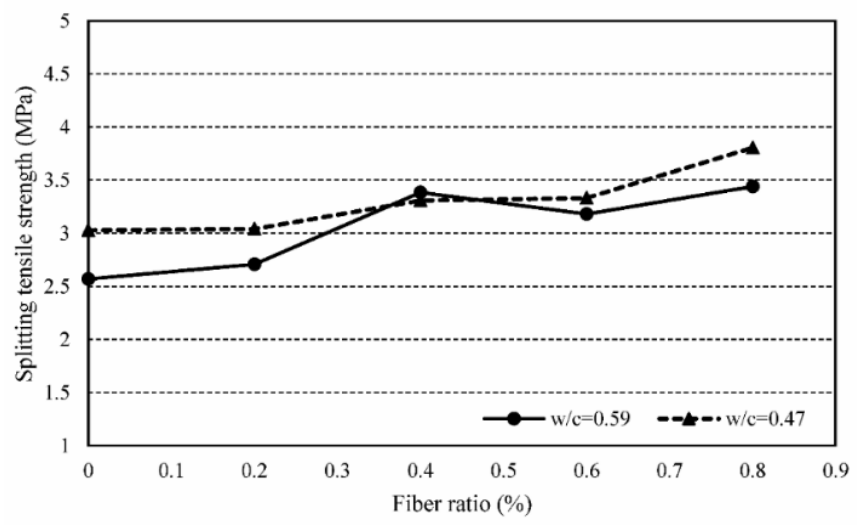

Figure 6. Variation of splitting tensile strength results

The static modulus of elasticity test results from the concrete incorporated with and without BF for 0.59 and $0.47 \mathrm{w} / \mathrm{c}$ ratios are given in Figure 7. The figure shows that the sample without BF has the lowest static modulus of elasticity value and the increase in the amount of fiber utilization increases static modulus of elasticity value. The highest static modulus of elasticity result was obtained from the concrete mixture with $0.8 \% \mathrm{BF}$ incorporation for the both w/c ratios. Based on the comparison with the control concretes, static modulus of elasticity results from the concretes produced with $0.8 \% \mathrm{BF}$ content have increased by about $16 \%$ for the both $\mathrm{w} / \mathrm{c}$ ratios. 


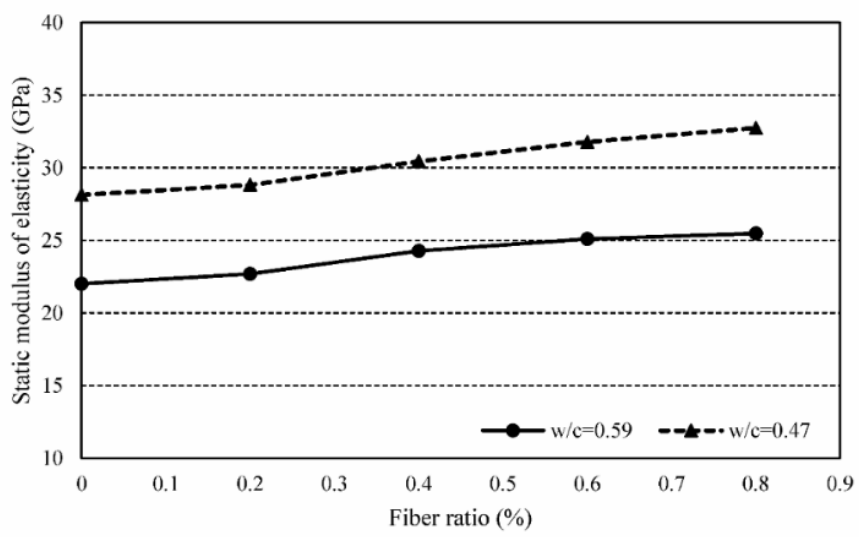

Figure 7. Variation of the static modulus of elasticity results

\section{Multi-Objective Optimization (MOO)}

The response surface method (RSM) used as a widespread optimization method collects statistical techniques of experiment design, regression and optimization analyses (Whitcomb and Anderson, 2004). The procedure of RSM is initiated with the modelling that fits the obtained data. In the second stage, optimization process is conducted to define the optimal solution for the response surface of the model chosen. RSM has been performed on the factors of 2 and the responses of 6 in the present experimental study. These two factors are the BF contents and the water to cement ratios considered, and the responses are used as cost, slump, static modulus of elasticity, compressive, flexural and splitting tensile strengths. The objective of the presented optimization study is to specify the optimum values for the BF content and the w/c ratio while maximizing the parameters of slump, static modulus of elasticity, compressive, flexural and splitting tensile strengths, and minimizing the cost.

Two optimization problems based on the mechanical performance and the cost of concrete incorporated with BF are formulated to specify the optimum values for BF content and w/c ratio. Initially, the optimization analysis is conducted based on only performance of concrete. In this optimization analysis, the characteristic goal for the responses of slump, static modulus of elasticity and the variables of compressive, splitting tensile and flexural strengths are maximized. Since the performed optimization aims at identifying the optimum fiber content and w/c ratio for the concrete incorporated with BF, the characteristic goal for the factors of fiber content and w/c ratio are considered to be in range. The second optimization analysis is conducted considering both the performance and the cost of concrete. In this optimization analysis the BF content and the w/c ratio are optimized simultaneously for maximizing the responses of slump, static modulus of elasticity and the variables of compressive, flexural and splitting tensile strengths along with minimizing the cost.

The characteristics goals for the variables in the optimization analyses performed are provided in Table 4. Figure 8 illustrates the relationship between the factors and responses considered in the MOO analysis undertaken.

Table 4. Definitions for the variables in the MOO problem

\begin{tabular}{|c|c|c|c|}
\hline Variables & Goal & Lower limit & Upper limit \\
\hline Fibre content $(\%)$ & In range & 0 & 0.8 \\
\hline $\mathrm{w} / \mathrm{c}$ ratio & In range & 0.47 & 0.59 \\
\hline Slump (cm) & Maximize & 7 & 18 \\
\hline Compressive strength $(\mathrm{MPa})$ & Maximize & 31.87 & 55 \\
\hline Splitting tensile strength (MPa) & Maximize & 2.57 & 3.80 \\
\hline Flexural strength (MPa) & Maximize & 5.3 & 6.63 \\
\hline Static modulus of elasticity (GPa) & Maximize & 22.01 & 32.74 \\
\hline Cost $(\$)$ & Minimize & 27.91 & 217.71 \\
\hline
\end{tabular}




\section{Mechanical Performance of Basalt Fibre Reinforced Concretes}
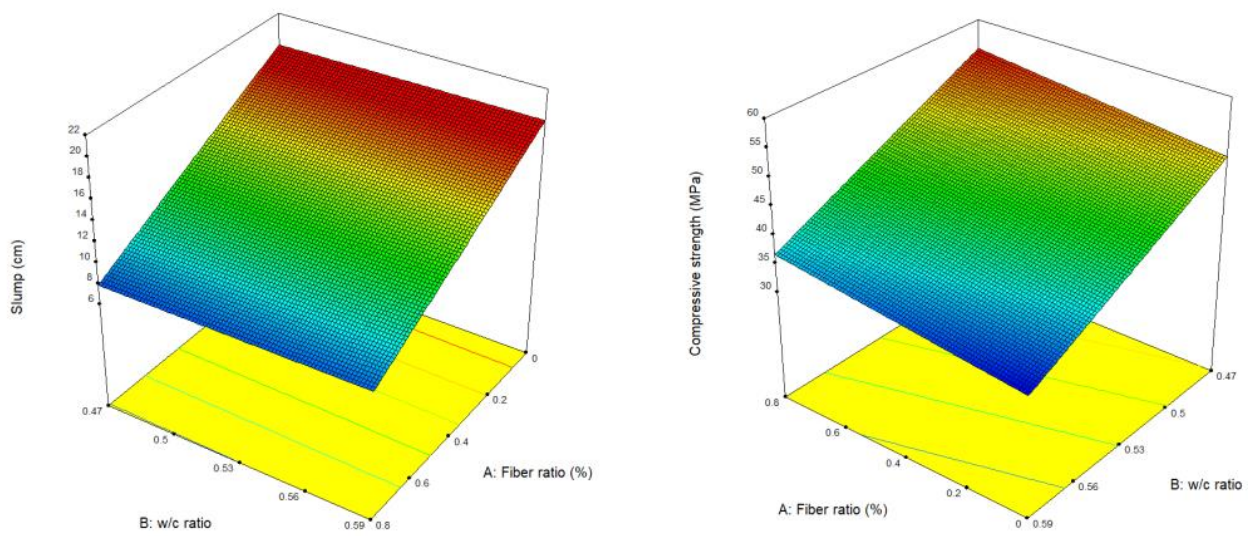

(a)

(b)
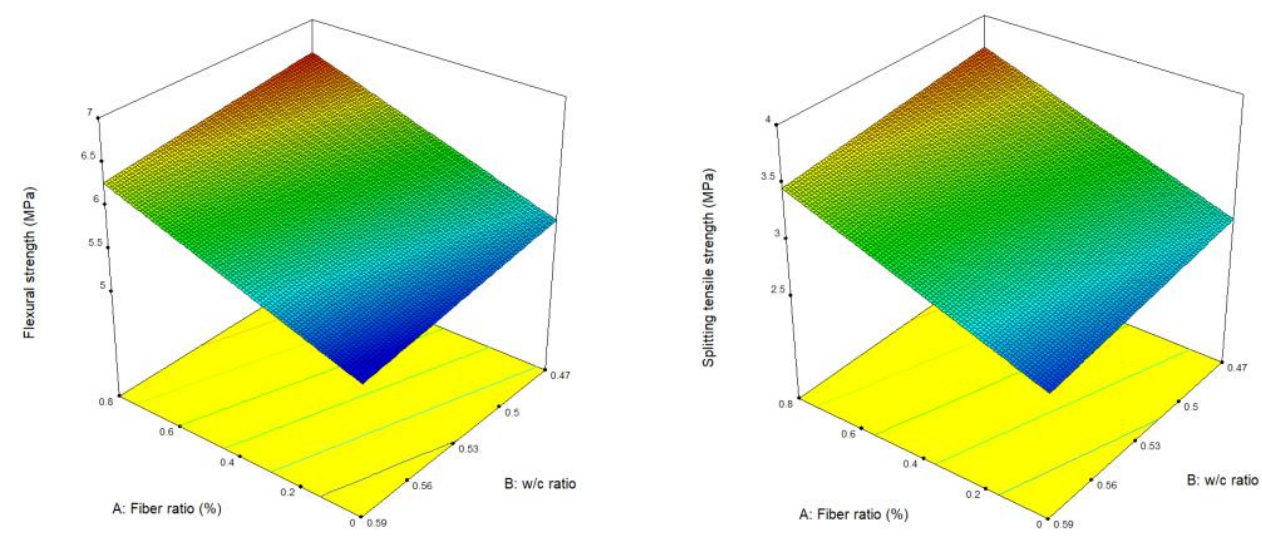

(c)
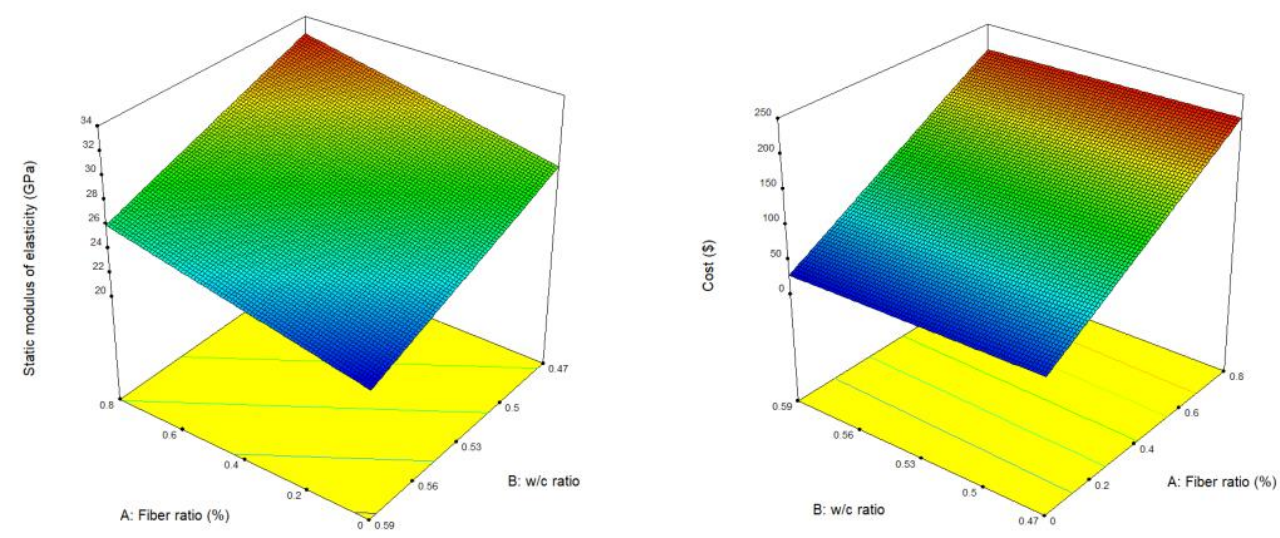

(e)

Figure 8. The influence of fiber reinforcement rate and water to cement ratio on (a) slump, (b) compressive strength, (c) flexural strength, (d) splitting tensile strength, (e) static modulus of elasticity and (f) cost

Figures 9(a) and 9(b) show the variation of desirability functions obtained from the performed optimization analyses by considering the only the mechanical performance of concrete and both the mechanical performance and the cost of concrete, respectively. The obtained solutions for these optimizations are given in Table 5. Table 5 shows that the defined lower and upper limits are met, and the desirability values are in the reasonable range and the optimum w/c ratio for the both optimization analyses is obtained as 0.47 . Table 5 also shows that the optimum fiber content values are obtained as 0.563 and 0.356 considering the only mechanical performance of concrete and both the mechanical performance and the cost of concrete, respectively. The optimized result with the highest desirability 
value is achieved for the concrete sample incorproted with the BF content of $0.356 \%$ and the w/c ratio of 0.47 when the mechanical performance and the cost of concrete are considered.
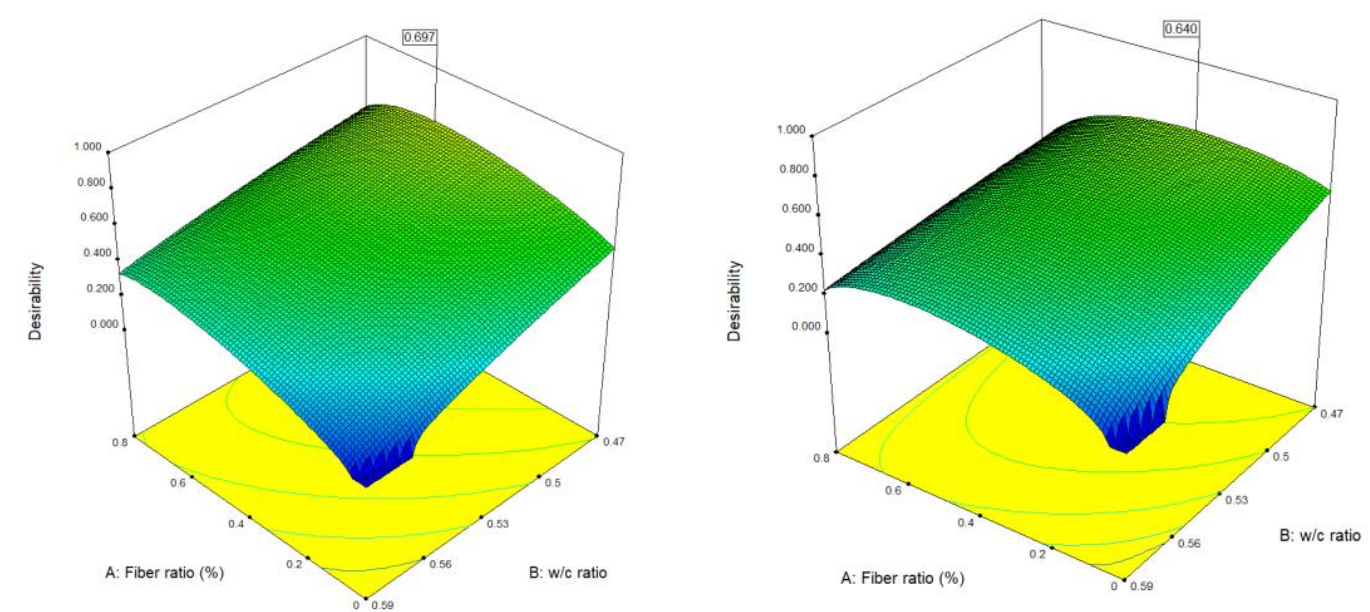

Figure 9. Variation of desirability function based on (a) the mechanical performance and (b) the mechanical performance and cost of the concrete incorporated with $\mathrm{BF}$

Table 5. The results of MOO anaylses

\begin{tabular}{lcc}
\hline \multirow{2}{*}{ Variables } & Optimization 1 & Optimization 2 \\
\cline { 2 - 3 } & Optimum values and expected response \\
\hline Fibre content (\%) & 0.562 & 0.356 \\
w/c ratio & 0.47 & 0.47 \\
Slump (cm) & 11.166 & 13.999 \\
Static modulus of elasticity (GPa) & 31.257 & 30.149 \\
Splitting tensile strength (MPa) & 3.468 & 3.259 \\
Compressive strength (MPa) & 53.294 & 52.008 \\
Flexural strength (MPa) & 6.297 & 6.030 \\
Cost $(\$)$ & --- & 115.858 \\
Desirability & 0.697 & 0.640 \\
\hline
\end{tabular}

\section{Modelling of Modulus of Elasticity}

Physically the modulus of elasticity (or elastic modulus) is a measure of the resistance of a material against deformation under any level of applied stress. It also reflects the stiffness of a material. The higher the elastic modulus is, the higher the stiffness of material is. Therefore, it is an important mechanical property of concrete used in the design. Because of quasi brittle nature of concrete, direct proportioning of the stress to the corresponding strain in the elastic region cannot provide elastic modulus of concrete. Therefore, some approaches have been developed to determine, static, dynamic, and flexural elastic moduli of concrete. The most commonly benefited elastic modulus value for general design purposes is static modulus of elasticity. Almost in all of the design codes, there are empirical relations benefited to predict static modulus of elasticity. The most famous ones are reported in design codes CEB-FIP (1990) and ACI 318R-05 (2008). The relations for ACI 318-05 (2008) model and CEBFIP (1990) model are given in Equations 1-2, respectively.

$E_{c}=0.043 w^{1.5} \sqrt{f_{c k}}$

$E_{c}=9500\left(f_{c k}+8\right)^{1 / 3}$

Where $E_{c}$ static elastic modulus (MPa), $w$ is unit weight of concrete $\left(\mathrm{kg} \mathrm{m}^{-3}\right), f_{c k}$ is characteristic strength of standard cylindrical specimen $(\phi 150 \times 300 \mathrm{~mm})$ in $\mathrm{MPa}$. 
In this study, experimental moduli of elasticity values of BF incorporated concretes were correlated with the square root of equivalent standard cylindrical $f_{c k}$ values $\left(\sqrt{f_{c k}}\right)$. The conversion from cube compressive strength to cylindrical was accomplished according to the relation given in Eq. 3 $f_{c k}=c \times f_{c k, c u b e}$

Where $\mathrm{c}$ is conversion factor (taken as 0.8 ), and $f_{c k, c u b e}$ is characteristic strength value of 150x150x150 mm cubic specimen. The obtained correlation yielded the following relation with a coefficient of determination of 0.9286 (Eq. 4)

$E_{c}=5472.1 \sqrt{f_{c k}}-4851$

In order to compare the proposed model in Eq. 4 with the available ones Figure 10 is plotted. Moreover, a few numbers of data presented by previous researchers for further comparison (Ayub et al., 2014b; K1z1lkanat et al., 2015; Dong et al., 2017). The data obtained from the previous studies are equivalent cylindrical compressive strength values and corresponding static modulus of elasticity values determined experimentally. Since the unit weight of concretes investigated in this study are approximately $2300 \mathrm{~kg} \mathrm{~m}^{-3}$, the ACI formula is simplified as Eq. 5 .

$E_{c}=4750 \sqrt{f_{c k}}$

Observing Figure 10 that it is seen that the proposed model has a close tendency to the ACI formula, however, CEB-FIP model has overestimation until $f_{c k}=60 \mathrm{MPa}$, then yields similar values. For the strength values of higher than $70 \mathrm{MPa}$ the three relations gave similar results, however for the lower strength values, especially $f_{c k}<40 \mathrm{MPa}$ the proposed model seems to perform better than the others.

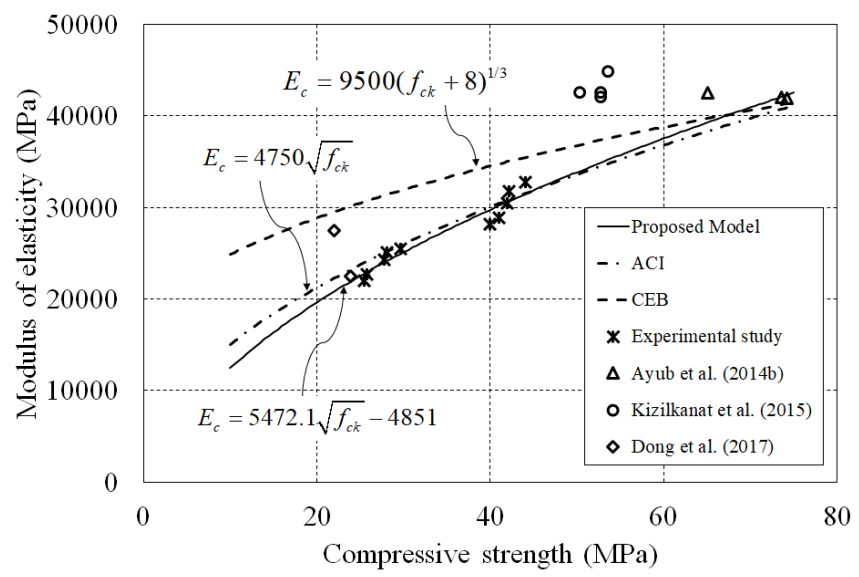

Figure 10. Comparison of the prediction capability of the proposed model with the available ones defined in the design codes ACI 318 (2008) and CEB-FIP (1990)

\section{CONCLUSION}

Based on the findings obtained from the presented research the following conclusions can be drawn.

- The slump values of concrete mixes gradually decrease with an increasing amount of BF for the both $\mathrm{w} / \mathrm{c}$ ratios. The use of $0.8 \% \mathrm{BF}$ in concrete induces a decrease approximately $61 \%$ and $56 \%$ for 0.59 and $0.47 \mathrm{w} / \mathrm{c}$ ratios, respectively.

- The addition of BFs to the concrete slightly increases the compressive strength results. 
- The flexural strength values of the concrete specimens increase gradually as the ratio of BF increases from 0 to $0.8 \%$ for the both w/c ratios. Considering the flexural strength performance of the concretes, the utilization of $0.8 \% \mathrm{BF}$ appears to be promising.

- The highest test result for splitting tensile strength is obtained from the sample containing $0.8 \% \mathrm{BF}$. Comparing with the concrete without $\mathrm{BF}$, the test results of splitting tensile strength for the sample with $0.8 \% \mathrm{BF}$ incorporation are increased by about $34 \%$ and $26 \%$ for 0.59 and 0.47 w/c ratios, respectively.

- Based on the comparison with the control concretes, the static modulus of elasticity results from the concretes produced with $0.8 \%$ BF content have increased by about $16 \%$ for the both w/c ratios.

- The optimized result with the highest desirability is obtained for the mixture with the BF content of $\% 0.356$ and $0.47 \mathrm{w} / \mathrm{c}$ ratio when the mechanical performance and the cost of concrete are considered.

- Analytical modelling of the experimental data provided an estimation model which has a reasonable correlation with the available models (ACI 318-05, and CEB-FIP) and the experimental values reported in previous researches.

\section{ACKNOWLEDGMENTS}

This study was supported by Harran University Scientific Research Centre (HÜBAK), Project no: 18046.

\section{REFERENCES}

ACI 318, Building Code Requirements for Structural Concrete and Commentary (318R-08), American Concrete Institute, Farmington Hills, MI, 2008.

Alnahhal W, Aljidda O, 2018. Flexural Behavior of Basalt Fibre Reinforced Concrete Beams with Recycled Concrete Coarse Aggregates. Construction and Building Materials, 169: 165-178.

Arivalagan S, 2012. Study on the Compressive and Split Tensile Strength Properties of Basalt Fibre Concrete Members. Global Journal of Researches in Engineering Civil and Structural Engineering, 12 (4): 23-28.

ASTM C39, Standard Test Method for Compressive Strength of Cylindrical Concrete Specimens, ASTM International, West Conshohocken, PA, 2018.

ASTM C469, Standard Test Method for Static Modulus of Elasticity and Poisson's Ratio of Concrete in Compression, ASTM International, West Conshohocken, PA, 2014.

ASTM C496, Standard test method for split tensile strength of cylindrical concrete specimens, ASTM International, West Conshohocken, PA, 2017.

ASTM C78, Standard test method for flexural strength of concrete (using simple beam with third-point loading), ASTM International, West Conshohocken, PA, 2016.

Ayub T, Shafiq N, Nuruddin MF, 2014a. Effect of Chopped Basalt Fibers on the Mechanical Properties and Microstructure of High Performance Fiber Reinforced Concrete. Advances in Materials Science and Engineering, Article ID 587686, 14 pages.

Ayub T, Shafiq N, Nuruddin MF, 2014b. Mechanical Properties of High-performance Concrete Reinforced with Basalt Fibres. Procedia Engineering, 77: 131-139.

Borhan TM, 2012. Properties of Glass Concrete Reinforced with Short Basalt Fibre. Materials and Design 42: $265-271$.

Borhan TM, 2013. Thermal and Mechanical Properties of Basalt Fibre Reinforced Concrete. World Academy of Science, Engineering and Technology, 7 (4): 334-337.

Budkonstruktsiya LLC, Technobasalt-Invest, 2013. Test conclusions on tensile strength in bending of Basalt Fibre concrete. Results obtained by the Research and Development enterprise Budkonstruktsiya LLC. 
CEB-FIP, CEB-FIP model code, Thomas Telford Services Ltd, Thomas Telford House, 1 Heron Quay, London E14 4JD, for the Comite Euro-International du Beton. EPF Lausanne, Case Postale 88, CH to 15 Lausanne, Switzerland, 1990.

Chen B, Liu J, 2005. Contribution of Hybrid Fibres on the Properties of the High Strength Lightweight Concrete Having Good Workability. Cement and Concrete Research, 35 (5): 913-917.

Chen F, 2013. An Experimental Study on Mechanical Properties of Basalt Fibre Reinforced Concrete. Applied Mechanics and Materials, 405-408: 2767-2770.

Deák T, Czigány T, 2009. Chemical Composition and Mechanical Properties of Basalt and Glass Fibres: a Comparison. Textile Research Journal, 79 (7): 645-651.

Dong JF, Wang QY, Guan ZW, Material Properties of Basalt Fibre Reinforced Concrete Made with Recycled Earthquake Waste. Construction and Building Materials, 130: 241-251.

Elshafie S, Whittleston G, 2015. Review of the Effect of Basalt Fibre Lengths and Proportions on the Mechanical Properties of Concrete. IJRET: International Journal of Research in Engineering and Technology, 4 (1): 458-465.

Fiore V, Di Bella G, Valenza A, 2011. Glass-Basalt/Epoxy Hybrid Composites for Marine Applications. Materials and Design, 32 (4): 2091-2099.

Fiore V, Scalici T, Di Bella G, Valenza A, 2015. Review on Basalt Fibre and Its Composites. Composite Part B: Engineering, 74: 74-94.

Jiang C, Fan K, Wu F, Chen D, 2014. Experimental Study on the Mechanical Properties and Microstructure of Chopped Basalt Fibre Reinforced Concrete. Materials and Design, 58: 187-193.

Jiang CH, McCarthy TJ, Chen D, Dong Q, 2010. Influence of Basalt Fibre on Performance of Cement Mortar. Key Engineering Materials, 426-427: 93-96.

Jun W, Ye Z, 2010. Experimental Research on Mechanical and Working Properties of Non-Dipping Chopped Basalt Fibre Reinforced Concrete. 3rd International Conference on Information Management, Innovation Management and Industrial Engineering, Kunming, China, November 26-28, 2010, pp.635-637.

Kabay N, 2014. Abrasion Resistance and Fracture Energy of Concretes with BF. Construction of Building Materials. 50: 95-101.

Ketan G, Kulkarni SM, 2012. The Performance of Basalt Fibre in High Strength Concrete. Journal of Information, Knowledge and Research in Civil Engineering, 2 (2): 117-124.

Kızılkanat AB, Kabay N, Akyüncü V, Chowdhury S, Akça, AH, 2015. Mechanical Properties and Fracture Behavior of Basalt and Glass fiber reinforced Concrete: An Experimental Study. Construction and Building Materials, 100: 218-224.

Lopresto V, Leone C, De Iorio I, 2011. Mechanical Characterization of Basalt Fibre Reinforced Plastic. Composite Part B: Engineering, 42 (4): 717-723.

Ma J, Qiu X, Cheng L, Wang Y, 2010. Experimental Research on the Fundamental Mechanical Properties of Presoaked BF Concrete. The 5th International Conference on FRP Composites in Civil Engineering, Beijing, China, September 27-29, 2010, 2010, pp.85-88.

Mohammadi Y, Singh SP, Kaushik SK, 2008. Properties of Steel Fibrous Concrete Containing Mixed Fibres in Fresh and Hardened State. Construction and Building Materials, 22 (5): 956-965.

Palchik PP, 2011. On Control Testing of Fiber-Concrete Samples to Determine Their Compression and Tensile Strength at Bending. Protocol No 64-1-11, Kyiv National University of Construction and Architecture.

Poznya OR, Kirakevych II, Stechyshyn MS, 2014. Properties of Self-Compacting Concrete with Basalt Fiber. Lviv Polytechnic National University, Department of Building Production, 149-154.

Raj S, Gopinath S, Iyer NR, 2014. Compressive Behavior of BF Reinforced Composite. International Journal of Structural Analysis \& Design, 1 (1), 49-53.

Sim J, Park C, Moon DY, 2005. Characteristics of Basalt Fibre as a Strengthening Material for Concrete Structures. Composite Part B: Engineering, 36 (6-7): 504-512. 
Singaravadivelan R, Chinnadurai P, Karthikeyan G, Muthuramu KL, Ramamoorthy NV, 2012. An Experimental Study Has Been Carried Out to Evaluate the Behavior of Concrete Elements Using Basalt Chopped Strands Fiber. International Conference on Chemical, Bio-Chemical and Environmental Sciences, Singapore, December 14-15, 2012, pp.31-34.

Solikin M, 2012. High Performance Concrete with High Volume Ultra Fine Fly Ash Reinforced with Basalt Fibre. RMIT University School of Civil, Environmental and Chemical Engineering, Melbourne, Australia, Ph.D. Thesis (Printed).

Wang X, Wu Z, Wu G, Zhu H, Zen F, 2013. Enhancement of Basalt FRP by Hybridization for Long-Span CableStayed Bridge. Composite Part B: Engineering, 44 (1): 184-192.

Wang Y, Wu HC, Li VC, 2000. Concrete Reinforcement with Recycled Fibers. Journal of Materials in Civil Engineering, 12 (4): 314-319.

Wei B, Cao H, Song S, 2010. Tensile Behaviour Contrast of Basalt and Glass Fibres after Chemical Treatment. Materials and Design, 31 (9): 4244-4250.

Wei B, Cao HL, Song SH, 2011. Degradation of Basalt Fibre and Glass Fibre/Epoxy Resin Composites in Seawater. Corrosion Science, 53 (1): 426-431.

Whitcomb PJ, Anderson MJ, 2004. RSM Simplified: Optimizing Processes Using Response Surface Methods for Design of Experiments. Taylor \& Francis, New York, 304p.

Wu H, Zhao J, Wang Z, 2013. Study on Micro-Structure and Durability of Fiber Concrete. Research Journal of Applied Sciences, Engineering and Technology, 5 (2): 659-664.

Yazıc1 S, Inan G, Tabak V, 2007. Effect of Aspect Ratio and Volume Fraction of Steel Fiber on the Mechanical Properties of SFRC. Construction and Building Materials, 21 (6): 1250-1253. 